\title{
ProQuest
}

Databases selected: Multiple databases...

\section{The Effect of Orbital Forcing on the Mean Climate and Variability of the Tropical Pacific}

A Timmermann, S J Lorenz, S-I An, A Clement, S-P Xie. Journal of Climate. Boston: Aug 15, 2007. Vol. 20, Iss. 16; pg. 4147,13 pgs

\begin{abstract}
Summary)
Using a coupled general circulation model, the responses of the climate mean state, the annual cycle, and the EI Niño-Southern Oscillation (ENSO) phenomenon to orbital changes are studied. The authors analyze a 1650-yr-long simulation with accelerated orbital forcing, representing the period from $142000 \mathrm{yr}$ B.P. (before present) to $22900 \mathrm{yr}$ A.P. (after present). The model simulation does not include the time-varying boundary conditions due to ice sheet and greenhouse gas forcing. Owing to the mean seasonal cycle of cloudiness in the off-equatorial regions, an annual mean precessional signal of temperatures is generated outside the equator. The resulting meridional SST gradient in the eastern equatorial Pacific modulates the annual mean meridional asymmetry and hence the strength of the equatorial annual cycle. In turn, changes of the equatorial annual cycle trigger abrupt changes of ENSO variability via frequency entrainment, resulting in an anticorrelation between annual cycle strength and ENSO amplitude on precessional time scales. [PUBLICATION ABSTRACT]
\end{abstract}

Full Text (6556 words)

Copyright American Meteorological Society Aug 15, 2007

\section{[Headnote]}

ABSTRACT

Using a coupled general circulation model, the responses of the climate mean state, the annual cycle, and the El NiñoSouthern Oscillation (ENSO) phenomenon to orbital changes are studied. The authors analyze a 1650-yr-long simulation with accelerated orbital forcing, representing the period from $142000 \mathrm{yr}$ B.P. (before present) to $22900 \mathrm{yr}$ A.P. (after present). The model simulation does not include the time-varying boundary conditions due to ice sheet and greenhouse gas forcing. Owing to the mean seasonal cycle of cloudiness in the off-equatorial regions, an annual mean precessional signal of temperatures is generated outside the equator. The resulting meridional SST gradient in the eastern equatorial Pacific modulates the annual mean meridional asymmetry and hence the strength of the equatorial annual cycle. In turn, changes of the equatorial annual cycle trigger abrupt changes of ENSO variability via frequency entrainment, resulting in an anticorrelation between annual cycle strength and ENSO amplitude on precessional time scales.

\section{Introduction}

The EI Niño-Southern Oscillation (ENSO) is a coupled tropical mode of interannual climate variabilti that involves oceanic dynamics (Jm 1997) as well as large-scale atmospheric changes (Bjerknes 1969; Gill 1980). Through anomalous diabatic heating El Niño and La Niña conditions excite mendionally propagating atmospheric Rossby waves that influence weather conditions even in high latitudes.

Recent greenhouse warming simulations performed with ENSO-resolving coupled general circulation modds (CGCMs) have revealed that the projected amp[i. tude and $\mathrm{n}$ of fumre tropical padfic warming (Timmermann et al. 1999; Collins $2 \mathrm{~m}$. Collins at al. 2QQ5) and ${ }^{\wedge}$ fe of \pm e torial annual cycle (Timmermann et aL 20CAa) and ENSO (Timmermann e\{ a, im. Timmermann 2001; Philip and van Qldenborgh 2(?)6; Guüyardi 2006) to anthropogenic ciimate change \&? \& highly modd dependent Constraining this uncertainty is an important challenge for the climate community.

A possible way to assess the sensitivity of ENSO to climate perturbations is to study its behavior under past climate conditions. Past ENSO variability has been reconstructed for time slices throughout the last $120000 \mathrm{yr}$ (Sandweiss et al. 1996; Hughen et al. 1999; Rodbell et al. 1999; Rittenour et al. 2000; Corrège et al. 2000; Cole 2001; Tudhope et al. 2001; Moy et al. 2002; Andrus et al. 2002; Cobb et al. 2003). These reconstructions suggest that ENSO was active during the last interglacial about 125000 years ago and was probably reduced in its activity during the early to midHolocene (9000-7000 yr ago). One important component of late-Pleistocene climate variations is the orbital forcing, 
which modulates the phase and amplitude of the annual cycle of shortwave radiation due to changes in obliquity, precession, and eccentricity.

The response of the tropical climate system to orbital changes has been studied using intermediate coupled models (Clement et al. 1999, 2001) and general circulation models (DeWitt and Schneider 1998, 2000; Codron 2001; OttoBliesner 1999; Liu et al. 2000; OttoBliesner et al. 2003; Clement et al. 2004). Some of these simulations exhibit an early to mid-Holocene ENSO suppression, in accordance with the different paleo-ENSO reconstructions (Tudhope et al. 2001; Moy et al. 2002). Because of the tight coupling between ENSO and the seasonal cycle (Jin et al. 1994; Tziperman et al. 1994; Chang et al. 1994), a prerequisite for such modeling studies is that the tropical annual cycle in the Pacific is simulated reasonably well. It is expected that ENSO activity will be affected by changes in the mean state and the seasonal cycle. However, many coupled general circulation models fail to simulate the equatorial annual cycle in the Pacific realistically (Mechoso et al. 1995; Latif et al. 2001). This is due to the delicate balance of physical processes that transform a semiannual forcing on the equator into an annual cycle signal in winds, temperature, and mixed layer and thermocline depth in the eastern equatorial Pacific.

One key element for the generation of the equatorial annual cycle is the northern position of the intertropical convergence zone (ITCZ) and the attendant meridional temperature asymmetry around the equator, both of which are preconditioned by the land-sea contrasts in the eastern equatorial Pacific area (Philander et al. 1996) and the presence/absence of an Atlantic meridional overturning circulation (AMOC) (Timmermann et al. 2007) and maintained by air-sea interactions (Xie 1996).

This asymmetry generates cross-equatorial winds, which in turn cool the southern tropical eastern Pacific by increased evaporation, upwelling, and mixing. North of the equator, however, the cross-equatorial winds weaken, which leads to a warming relative to the southern tropical Pacific due to reduced evaporation (as compared to the meridionally symmetric state) and reduced mixing. This north-south temperature asymmetry is further amplified by the generation of low-level stratus clouds that form over the cold waters and lead to increased reflection of solar radiation. The north-south temperature gradient in turn generates cross-equatorial winds as a result of the Gill response (Gill 1980 ) and the Lindzen-Nigam boundary layer response (Lindzen and Nigam 1987). These positive air-sea feedbacks keep the ITCZ north of the equator. In fact, without the continental asymmetries, a Southern Hemispheric position for the ITCZ in the eastern tropical Pacific would be another possible equilibrium state. However, the equatorial position of the ITCZ is unstable (Xie 1997). With the changing seasons north-south asymmetry changes as well as the strength of the cross-equatorial trade winds. This provides the seeding for the annual cycle of SST on the equator. In addition, coupled air-sea interactions (Xie 1994; Li and Philander 1996; Philander et al. 1996) involving evaporative cooling, mixing, and stratus clouds generate a westward-propagating equatorial zonal mode with near-annual frequency that intensifies the annual wind forcing and, in turn, the equatorial annual cycle of SST. This positive feedback leads to the establishment of a coupled annual cycle in the eastern and central equatorial Pacific. Physical processes responsible for the generation of the annual cycle in the eastern equatorial Pacific are thus distinct from those that govern the interannual ENSO mode.

To study the influence of orbital forcing over the last $500000 \mathrm{yr}$ on ENSO, Clement et al. $(1999,2001)$ used an intermediate ENSO model. Because of the prescribed annual cycle in the model, the anomalous annual cycle simulated in response to orbital forcing arises primarily via ENSO physics that involves air-sea interactions in the zonal direction. The main conclusion of those studies is that the precessional cycle with a periodicity of about 19-23 ka has an influence on the period and amplitude of ENSO and, via nonlinear rectification processes, also on the mean state. However, the simulated mean state changes do not agree with recent temperature reconstructions from the eastern equatorial Pacific (Lea et al. 2000) both in terms of phase and amplitude, indicating that greenhouse gas forcing, albedo, and topographic changes of the ice sheets also played a major role in determining tropical temperatures throughout the late Pleistocene (Liu et al. 2002; Timmermann et al. 2004b).

The goal of our paper here is not to simulate the climate evolution of the last $142000 \mathrm{yr}$ more realistically by including, for example, orographic ice sheet forcing and greenhouse gas effects, but rather to per- form an idealized modeling study, similar to Clement et al. $(1999,2001)$, that will help to understand how orbital forcing and its modulation of the annual cycle of incoming shortwave radiation affects the mean climate, the annual cycle, and ENSO variability in the eastern equatorial Pacific. Our focus is on the relevant mechanisms rather than on the detailed past climate trajectory. Hence, the results should not be directly compared to paleo-proxy records for ENSO. Further studies have to be conducted in the future to take into account the role of other time-varying boundary conditions (Timm and Timmermann 2007).

The paper is organized as follows. In section 2 the CGCM is described. Section 3 presents the basic mechanism of orbitally driven ENSO variance changes. In section 4 a mechanism is proposed that explains the precessional variations of the meridional asymmetry. Section 5 summarizes the main results and a discussion is provided. Implications for the comparison of climate model simulations and ENSO proxies are discussed. 


\section{Model description}

The CGCM used in this study is the global atmosphere-ocean-sea ice model ECHO-G [ECHAM and the global Hamburg Ocean Primitive Equation (HOPE-G); Legutke and Voss 1999; Min et al. 2005]. The ocean component is HOPE-G, which uses a horizontal resolution of $2.8^{\circ}$ except in the Tropics where an equatorial refinement in the meridional direction of $0.5^{\circ}$ is used. The model equations are solved for 20 unevenly spaced vertical levels using the Pacanowski and Philander (1981) mixing scheme. The atmospheric component is ECHAM4 (Roeckner et al. 1996) in T30 resolution with 19 vertical levels. Constant greenhouse gas concentrations $(280 \mathrm{ppm} \mathrm{CO} 2,700 \mathrm{ppb}$ for $\mathrm{CH} 4$, and $265 \mathrm{ppb}$ N2O) for the preindustrial era are prescribed. Surface background albedo, vegetation ratio, leaf area index, distribution of continents and oceans, and orographic forcing are kept constant at their present values throughout the simulation.

To prevent strong model drift the coupled model runs are performed with annual mean flux correction fields for both heat and freshwater fluxes. The seasonal cycle itself is not flux corrected. The orbitally induced SST anomalies in our model simulation range from -4 to $+4^{\circ} \mathrm{C}$ with much smaller values in the Tropics. We assume that this is still in the linearization range (Sausen et al. 1988) for which the present-day flux correction can be applied. A more detailed analysis of the effect of annual mean flux corrections on the orbital modulation of ENSO and the annual cycle is beyond the scope of the present paper.

The ECHO-G model, and in particular its representation of the tropical Pacific annual cycle and ENSO, are described in more detail in Min et al. (2005). The simulated amplitude of the equatorial annual cycle of SST in the eastern Pacific is underestimated by about $40 \%$, possibly due to an underestimation of the mean meridional temperature asymmetry. The ECHO-G model is capable of simulating ENSO-like variability as reported by Rodgers et al. (2004) and Min et al. (2005). However, as a result of tropical wind biases the ENSO mode exhibits an unrealistically strong biennial component, similar to that of the ECHAM4/Ocean Isopycnal Model (OPYC3) simulation (Timmermann et al. 1999). Furthermore, it should be noted here that the ECHO-G model exhibits an unrealistically strong double ITCZ in the central to eastern tropical Pacific. This model bias may have implications for the simulated sensitivity of the ITCZ to orbital forcing, as will be discussed below. Furthermore, the biennial regime in which ENSO operates exhibits a particular sensitivity to annual cycle changes.

We do not expect the model to reproduce the time evolution of the real ENSO system throughout the last $142000 \mathrm{yr}$. Neglecting the time-varying boundary conditions of the ice sheets and greenhouse gas concentrations may lead to mismatches between simulated and reconstructed ENSO variability. Our primary aim is to study possible response mechanisms of the tropical climate system to orbital forcing.

A 1650-yr-long simulation was performed (Lorenz and Lohmann 2004; Felis et al. 2004) in which latitudinally dependent orbital forcing is applied with an acceleration factor of 100 in time. The model starts with the orbital configuration corresponding to the year $142 \mathrm{ka} \mathrm{B.P.} \mathrm{(ka} \mathrm{B.P.} \mathrm{\equiv 1000} \mathrm{years} \mathrm{before} \mathrm{present)} \mathrm{and} \mathrm{ends} \mathrm{in} \mathrm{the} \mathrm{year} 22.9$ ka A.P. (ka A.P. $\equiv 1000$ years after present). Surface temperatures in particular in the tropical oceans adjust within 2-4 months to solar insolation changes. This helps to set up SST gradients, which ultimately drive wind changes and feed back onto the SST evolution. Hence we expect the tropical oceans to be in quasi-equilibrium even with the accelerated orbital forcing. Testing the effect of the acceleration technique with acceleration factors of 10 and 100 , Lorenz and Lohmann (2004) found that similar global surface air temperature patterns are simulated.

A detailed description of the acceleration technique and its advantages and disadvantages can be found in Timm and Timmermann (2007). Deviations from the nonaccelerated simulation are expected to occur in particular in the Southern Ocean, in regions of deep-water formation, large thermal inertia, and below the ther- mocline. The tropical response to precessional forcing is expected to be largely unaffected by the acceleration technique.

From Fig. 1 it becomes evident that the most dominant signal of the simulated mean climate change in the equatorial Pacific is generated by the obliquity cycle with a 41 ka periodicity rather than from the precessional cycles, which have small annual mean top-of-the-atmosphere radiative forcing variations on the equator, in accordance with the results of Jackson and Broccoli (2003) and Liu et al. (2003). We will, however, see that the annual mean meridional asymmetry is strongly modulated on precessional time scales. Furthermore, by comparing the eastern and western Pacific low-frequency SST variations simulated by the ECHO-G model, we observe in Fig. 1 a similar amplitude of the obliquity-driven temperature anomalies. This suggests that, in our simulation, the dynamical thermostat mechanism proposed by Clement et al. $(1996,1999,2001)$ and Cane et al. (1997) to explain the zonal asymmetry of the temperature response to homogenous radiative forcing plays only a minor role. This may be explained by the fact (Liu 1998) that on long time scales off-equatorial processes also become important in modulating the thermocline temperature and hence the thermocline feedback. 


\section{Frequency entrainment of ENSO}

As suggested by Chang et al. (1994) and Liu (2002), the amplitude of ENSO depends on the strength of the annual cycle in a rather complex manner. One extreme case is that the annual cycle is absent. In this case the simulated ENSO amplitude is determined simply by ENSO-relevant processes. The other extreme case is a very strong annual cycle forcing, which prevents the generation of interannual ENSO anomalies. This type of behavior can be found in many periodically driven nonlinear oscillatory systems. When the external forcing amplitude is moderately strong, the internal signal becomes locked in phase and frequency to the external signal, preventing chaotic and erratic bursts.

Two signals that exhibit phase locking are called "synchronized signals." If $\varphi(t)$ is the phase of the oscillator (ENSO) and $\psi(t)$ the phase of the driving force (annual cycle forcing), then the phase locking condition is given by $\mid n \varphi(t)-m \psi$ $(\mathrm{t}) \mid<$ const with $\mathrm{n}, \mathrm{m}$ being natural numbers. For periodic oscillators this is equivalent to the frequency locking condition $n \varphi=m \psi$. To adopt this concept to the tropical Pacific we have to note, however, that the true external forcing is provided by the equatorial semiannual and the off-equatorial annual top-of-the-atmosphere insolation. The annual cycle of winds is already a product of tropical air-sea interactions and can respond to interannual variability as well as the other way around.

To diagnose the interaction between annual cycle and ENSO in our CGCM we study the spectral characteristics of eastern equatorial Pacific SSTs in more detail. Figure 2 shows the Morlet wavelet spectrum (Torrence and Compo 1998) of simulated Niño-3 SST. Wavelet spectra, somewhat similar to evolutionary spectra, provide a time-resolving variance and phase spectrum.

The simulated interannual anomalies have a pronounced biennial period, indicative of a 1:2 frequency locking and synchronization between annual cycle and ENSO. This is an interesting type of self-organization of modes of climate variability in this model. Furthermore, we observe that the strength of the annual cycle and ENSO are modulated on the precessional time scale of about $21000 \mathrm{yr}$. Figure 2 reveals that in phases of strong ENSO variability, the annual cycle tends to be weak and vice versa. There are also shorter periods when both cycles can coexist. Hence, the synchronization characteristics between annual cycle and ENSO are modulated on orbital time scales. This finding supports the frequency entrainment hypothesis of Liu (2002).

To understand the relation between annual cycle strength, ENSO, and the background state in more detail, we focus on the shorter section from 142 to $107 \mathrm{ka} \mathrm{B.P.} \mathrm{Figure} 3$ shows the anomalous position of the ITCZ in the eastern equatorial Pacific and the meridional surface wind component on the equator. A warmer northeastern tropical Pacific (Fig. 4) (e.g., around 135-125 ka B.P.) leads to an enhancement of the cross-equatorial winds (Fig. 3). An intensification of the cross-equatorial winds leads to a northward shift of the wind convergence, leading to reduced Ekman pumping in the zone of high SST and reduced mixing and evaporation, thereby providing a positive air-sea feedback for the northeastern tropical Pacific warming.

Figures 3 and 4 reveal that the strength of the annual cycle is strongly correlated with the meridional gradient of temperatures and the meridional position of the ITCZ, thereby supporting the notion that the meridional gradient of SST, the position of the ITCZ, and the strength of the cross-equatorial trade winds control the strength of the equatorial annual cycle (Xie 1994).

Note also that in Fig. 3 the mean position of the anomalous zonally averaged ITCZ exhibits abrupt changes, whereas the orbital forcing varies smoothly in time. These transitions from a more symmetric to a more asymmetric state are driven by the strength of the orbital forcing and ultimately by the strength of the off-equatorial net shortwave forcing and the meridional SST gradient. 1

While the obliquity cycle dominates the annual mean changes in the equatorial Pacific (Fig. 1), changes in the seasonal cycle are strongly governed by the precessional cycle. This gives a rather complex rhythm of background state and seasonal cycle variations on which ENSO operates.

The next section addresses the question of why the annual mean meridional SST asymmetry in the eastern tropical Pacific is modulated on precessional time scales.

\section{Precessional cycle of the meridional asymmetry}

An important element of our diagnosed mechanism is the existence of a precessional cycle of the annual-mean meridional SST gradient and wind forcing. The variations of the annual-mean incoming solar radiation due to precessional forcing in the Tropics are close to zero. Yet, we have seen in the ECHO-G simulation a pronounced 
precessional cycle of precipitation and winds (Fig. 3), clouds (not shown), and temperature (Fig. 4). The origin of the precessional cycles of these variables can be qualitatively explained as follows.

For a given latitude (say $7^{\circ} \mathrm{N}$ ) the strength of the annual cycle of top-of-the-atmosphere insolation undergoes strong precessional and eccentricity cycles. Now suppose that, in a state with enhanced seasonal cycle in the northern tropical Pacific, the boreal summer insolation is $20 \mathrm{~W} \mathrm{~m} \mathrm{~m}^{\wedge}$ sup $-2^{\wedge}$ stronger than under normal conditions, whereas the boreal winter insolation is reduced by $20 \mathrm{~W} \mathrm{~m} \mathrm{~m}^{\wedge}$ sup $-2^{\wedge}$ from some normal background state. Without a seasonal cycle in clouds the annual mean precessional variations of the surface shortwave radiations are close to zero. However, there is a seasonal cycle of cloudiness in the off-equatorial region, and in particular of convective clouds in the Northern Hemisphere, due to the seasonal movement of the ITCZ. For reasons of simplification let us assume an albedo of 0.5 in boreal summer and 0.25 in boreal winter. This corresponds to a cloudiness of approximately 0.8 and 0.4 , respectively. 2 The surface shortwave radiation gain in summer is $10 \mathrm{~W} \mathrm{m \wedge}$ sup $-2^{\wedge}$ and the loss is $15 \mathrm{~W} \mathrm{~m}$ sup $2^{\wedge}$ in winter, giving a $-5 \mathrm{~W} \mathrm{~m} \mathrm{~m}^{\wedge}$ sup $-2^{\wedge}$ annual mean shortwave radiation anomaly. Thus a symmetric increase in the amplitude of the annual cycle top-of-the-atmosphere radiation leads to a net cooling due to the covariation between solar insolation and cloudiness. Similar processes are happening also in the Southern Hemisphere. In this simplified qualitative argument we have neglected the evolution of the full seasonal cycle and have instead focused on the extreme seasons in one hemisphere, which is not entirely justified.

To put these qualitative arguments in more quantitative terms we assume that, due to the northern mean position of the ITCZ, the orbitally driven changes of the annual mean strength of the cross-equatorial winds are proportional to the meridional SST and heating gradients (Fig. 4), the latter being controlled by shortwave forcing in the northern and southern Tropics $\left(Q^{\wedge}\right.$ sup $N^{\wedge \wedge} s u b s w^{\wedge}-Q^{\wedge} \sup S^{\wedge} \wedge$ sub $\left.s w^{\wedge}\right)$ and air-sea interactions. The indices $N$ and $S$ refer to the latitudes $\varphi=7^{\circ} \mathrm{N}$ and $\varphi=7^{\circ} \mathrm{S}$, respectively. Neglecting zonal asymmetries, the latitudinally dependent shortwave radiation absorbed at the earth's surface is a function of the incoming shortwave radiation $Q^{\wedge} \operatorname{sub} 0^{\wedge}(\varphi, t)$, the albedo, and the cloud cover $\mathrm{c}(\varphi, \mathrm{t})$ :

$Q^{\wedge} \operatorname{sub~} \operatorname{sw}^{\wedge}(\varphi, t)=\left(1-A^{\wedge} \operatorname{sub} o^{\wedge}\right)\left[1-A^{\wedge} \operatorname{sub~} c^{\wedge}(\varphi, t) c(\varphi, t)\right] Q^{\wedge} \operatorname{sub} 0^{\wedge}(\varphi, t) .(1)$

Here it is assumed that the surface albedo over the oceans is constant $\left(A^{\wedge} s u b o^{\wedge}=0.09\right)$. For purposes of simplicity $\operatorname{Ac}(\varphi, t)$, the mean cloud albedo, is assumed to be only a function of latitude $\varphi$. The cloudiness can be decomposed into an annual mean component $\mathrm{c}$ (where the overbar represents the long-term mean), an annual cycle component $\mathrm{c}^{\wedge}$ sub $a c y^{\wedge}$, and a residual component that captures other high- and low-frequency variations $\mathrm{c}^{\wedge}$ sub $\mathrm{R}^{\wedge}$ (i.e., $\mathrm{c}=\mathrm{c}+$ $c^{\wedge}$ sub $a c y^{\wedge}+c^{\wedge}$ sub $R^{\wedge}$ ). The seasonal cycle for the ECHO-G simulation is obtained using the entire simulation covering the orbital conditions from 142 to $22.9 \mathrm{ka}$ B.P. It is very similar to the seasonal cycle obtained by averaging only the present-day period in this simulation. Here we neglect the $\mathrm{c}^{\wedge} s u b \mathrm{R}^{\wedge}$ and focus our attention on the simulated and observed mean seasonal cycle of cloudiness, which are depicted for the northeastern and southeastern tropical Pacific in Fig. 5. Overall the ECHO-G underestimates the mean cloudiness, as compared to the Comprehensive Ocean-Atmosphere Data Set (COADS) observations (Oberhuber 1988). Furthermore, some small phase differences occur between the observed cloudiness and the simulated cloudiness in the tropical eastern Pacific. As will be shown below, such phase differences will play an important role in the exact timing of the precessional cycle of the annual cycle and ENSO.

Using $Q^{\wedge}$ sub $0^{\wedge}(\varphi)$ from Berger (1978), Ac $(\varphi)$ from the ECHO-G simulation, and $c^{\wedge}$ sub acy^ $(Q, t)$ from Fig. 5, we compute $\mathrm{Q}^{\wedge} \mathrm{sub} \mathrm{sw}^{\wedge}$ for an area average from $5^{\circ}$ to $12^{\circ} \mathrm{N}$ and $12^{\circ}$ to $5^{\circ} \mathrm{S}$. Figure 6 a shows the resulting low-frequency annual mean difference between the net incoming shortwave radiation in the north and the south $\left(\mathrm{Q}^{\wedge} \operatorname{sup~}^{\wedge}{ }^{\wedge} \operatorname{sub} \mathrm{sw}^{\wedge}\right.$ $-Q^{\wedge}$ sup $S^{\wedge}$ sub $\mathrm{sw}^{\wedge}$ ). For large positive values, the meridional heating gradient causes a northward shift of the ITCZ (Fig. 3), stronger cross-equatorial winds (Fig. 3), a stronger annual cycle (Fig. 6) and a weaker biennial ENSO cycle (see Fig. 2). Omitting cacy, the meridional heating asymmetry does not exhibit a precessional cycle. Furthermore, we have computed the meridional heating asymmetry using an incoming insolation $Q^{\prime \wedge}$ sub $0^{\wedge}(\varphi, t)$, which uses constant obliquity forcing. The resulting meridional heating asymmetry (not shown) is indistinguishable from the heating gradient shown in Fig. 6 a, suggesting that obliquity forcing does not play any significant role in driving the meridional heating gradient near the equator.

To test the sensitivity of the meridional heating to the seasonal cycle of cloudiness, we computed $\left(\mathrm{Q}^{\wedge} \operatorname{sup~} \mathrm{N}^{\wedge \wedge} \operatorname{sub}^{\wedge} \mathrm{sw}^{\wedge}\right.$ $-Q^{\wedge} \sup S^{\wedge} \wedge$ sub $s w^{\wedge}$ ). from the simulated $A^{\wedge} s u b c^{\wedge}(\varphi)$ and the observed present-day seasonal cycle of clouds (see Fig. 5). The result in Fig. $6 \mathrm{~b}$ clearly illustrates that relatively small changes in the phase of the annual cycle between observations and simulation can lead to phase differences on the order of 2000-3000 yr. This puts a severe modeling constraint on our ability to correctly simulate the reconstructed changes and timing of paleo-ENSO variability.

Apparently the annual modulation of the cloudiness together with the orbital forcing "seeds" a precessional cycle of the annual-mean meridional temperature gradient across the equator. This in turn will also lead to relatively weak precessional variations of the cloudiness, which we have not addressed here explicitly. Overall, we expect the 
precessional response of the deep clouds in the Northern Hemisphere to level off the seeding effect, while the lowlevel clouds in the Southern Hemisphere are expected to provide a positive feedback.

While the obliquity cycle affects the amplitude of the seasonal cycle, the increase in amplitude is symmetric around the equator (in contrast to the combined precessional-eccentricity effect). Hence the annual-mean meridional temperature gradient due to obliquity basically vanishes and so does its effect on the seasonal cycle on the equator. However, the annual mean solar radiation on the equator is still dominated by the obliquity cycle, as shown in Fig. 1.

\section{Summary and discussion}

The aim of this study was to understand the response of ENSO to orbital forcing changes. Orbital forcing changes have an impact on the phase and amplitude of the annual cycle, which in turn modulate ENSO. In certain areas of the parameter space of the tropical Pacific climate system, ENSO and the annual cycle are coupled in the sense that, when the annual cycle amplitude is large, ENSO activity is weak and vice versa. Based on our modeling evidence we propose that orbital ENSO modulations are strongly controlled by the strength of the annual cycle.

Our results illustrate that the Niño-3 SST in the ECHO-G model is determined by a set of coupled interactions that are highly sensitive to the precessional forcing. The main mechanisms by which orbital forcing alters the Pacific climatology and ENSO variability are summarized and illustrated schematically in Fig. 7: the precessional cycle modifies the time-averaged meridional asymmetry and hence, the strength of the cross-equatorial winds, via the mechanism outlined in section 4. According to Xie (1994), these winds drive changes in the strength of the annual cycle on the equator, which in turn determine the amplitude of the simulated ENSO variability through the nonlinear frequency entrainment mechanism (Chang et al. 1994). Whether the acceleration technique employed here has an effect on the phase and amplitude relationship that occurs as a result of the frequency entrainment mechanism has to be studied in more detail.

Our results exhibit some qualitative similarities with the results obtained in Clement et al. (1999) using an intermediate ENSO model (Zebiak and Cane 1987). In both the intermediate ENSO model and the CGCM simulations, ENSO can switch abruptly between dynamical states. Also, both studies illustrate that ENSO is most sensitive to precessional forcing, rather than to obliquity forcing. However, in contrast to the results of Clement et al. (1999), our simulated changes of ENSO variability on precessional time scales do not have a significant influence on the background state in the tropical Pacific. As shown in Fig. 1 the background state changes in the eastern equatorial Pacific are dominated by the obliquity cycle, rather than by the precessional cycle. Despite the fact that ENSO variability is highly skewed in the ECHO-G simulation (Rodgers et al. 2004), the background state rectification due to ENSO variance changes (Clement et al. 1999) does not seem to play a major role. There are also differences in the phase of the ENSO amplitude variations between the two models, suggesting that a direct comparison between different models and paleo-proxy data for ENSO should be made with great caution. The discrepancies between ECHO-G and the intermediate ENSO model results of Clement et al. (1999) may be related to the fact that in Clement et al. (1999), the insolation forcing is directly applied to the mixed layer, without consideration of an annual cycle of cloudiness. As shown in Fig. 6, the seasonal cycle of cloudiness plays a key role in determining the exact phase of the precessional response of the tropical Pacific. The mean seasonal cycle of cloudiness depends strongly on the simulated seasonal cycle of SST, which may be strongly model-dependent, even for state-of-the-art CGCMs. We hence expect that different CGCMs would simulate a different timing of the orbitally induced ENSO maxima and minima.

The ECHO-G control simulation exhibits 16-yr ENSO amplitude modulations (Rodgers et al. 2004) that correspond to a 1600 -yr cycle of ENSO activity using the acceleration technique and may contaminate the exact phases of the ENSO variance changes on time scales of less than about $2000 \mathrm{yr}$ (see Fig. 8). This further complicates a direct comparison of our modeling results with paleo-ENSO reconstructions. However, one general and robust feature emerges from our model simulation (Fig. 8): The amplitude of the annual cycle decreased from 16 to 4 ka b.p. and increased thereafter, whereas the variance of ENSO variability increased from 15 to $12 \mathrm{ka} \mathrm{B.P.} \mathrm{and} \mathrm{stayed} \mathrm{on} \mathrm{a}$ rather active level since then. Our model results are inconsistent with a pronounced early to mid Holocene ENSO suppression.

The sensitivity of ENSO to orbital variations may be an important component in ENSO's future long-term evolution (Fig. 2), a factor that has not been considered yet in previous studies.

Our study has neglected processes that may be important for late-Pleistocene ENSO variability such as variations in CO2, ice sheet orography, albedo (Timmermann et al. 2004b; An et al. 2004), and the state of the AMOC (Timmermann et al. 2005). Despite these omissions, it seems clear from all of the available modeling evidence that the interaction between ENSO and the annual cycle is important for our basic understanding of the sensitivity of the tropical Pacific climate to orbital forcing throughout the late Pleistocene. 
Acknowledgments. A. Timmermann, S.-I. An, and S.-P. Xie are supported by the Japan Agency for Marine-Earth Science and Technology (JAMSTEC) through its sponsorship of the International Pacific Research Center. A. Clement was supported by the National Science Foundation Paleoclimate program. S.-I. An was also supported by Grant R01-2006-000-10441-0 from the Basic Research Program of the Korea Science and Engineering Foundation and the Brain Korea 21 project.

\section{[Footnote]}

1 This abrupt regime behavior is reminiscent of the saddle point bifurcation behavior of the meridional tropical temperature asymmetry in response to the annual cycle amplitude that has been identified in a simplified tropical coupled model in Xie (1997). It should also be mentioned that CGCMs tend to produce a "double ITZC" in the eastern equatorial Pacific that is too close to the equator and too zonally oriented. Hence the flips between asymmetric and symmetric ITCZ states in Fig. 3 could also reflect flips between these "modes" of model climate.

2 The slightly exaggerated values are chosen here in order to make the argument as simple as possible.

\section{[Reference]}

REFERENCES

An, S.-I., A. Timmermann, L. Bejerano, F.-F. Jin, F. Justino, Z. Liu, and A. W. Tudhope, 2004: Modeling evidence for enhanced El Niño-Southern Oscillation amplitude during the Last Glacial Maximum. Paleoceanography, 19, PA4009, doi:10.1029/2004PA001020.

Andrus, C. F., D. E. Crowe, D. H. Sandweiss, E. Reitz, and C. S. Romanek, 2002: Otolith $\delta^{\wedge}$ sup $18^{\wedge} O$ records of midHolocene sea surface temperatures in Peru. Science, 295, 1508-1510.

Berger, A. L., 1978: Long-term variations of daily insolation and quaternary climatic changes. J. Atmos. Sci., 35, 2362-2367. Bjerknes, J., 1969: Atmospheric teleconnections from the equatorial Pacific. Mon. Wea. Rev., 97, 163-172.

Cane, M., A. Clement, A. Kaplan, Y. Kushnir, D. Pozdnyakov, R. Seager, S. Zebiak, and R. Murtugudde, 1997: Twentieth century sea surface temperature trends. Science, 275, 957-966.

Chang, P., B. Wang, T. Li, and L. Ji, 1994: Interactions between the seasonal cycle and the Southern Oscillation frequency entrainment and chaos in a coupled ocean-atmosphere model. Geophys. Res. Lett., 21, 2817-2820.

Clement, A. C, R. Seager, M. A. Cane, and S. E. Zebiak, 1996: An ocean dynamical thermostat. J. Climate, 9, 2190-2196. , and 1999: Orbital controls on the tropical climate. Paleoceanography, 14, 441-456.

$\overline{2375}$.

M. A. Cane, and R. Seager, 2001: An orbitally driven tropical source for abrupt climate change. J. Climate, 14, 2369-

$\overline{341 .}$

A. Hall, and A. Broccoli, 2004: The importance of precessional signals in the tropical climate. Climate Dyn., 22, 327-

Cobb, K., C. D. Charles, H. Cheng, and R. L. Edwards, 2003: El Niño/Southern Oscillation and tropical Pacific climate during the last millennium. Nature, 424, 271-276.

Codron, F., 2001: Sensitivity of the tropical Pacific to a change of orbital forcing in two versions of a coupled GCM. Climate Dyn., 17, 187-203.

Cole, J., 2001: A slow dance for El Niño. Science, 291, 1496-1497.

Collins, M., 2000: Understanding uncertainties in the response of ENSO to greenhouse warming. Geophys. Res. Lett., 27, 3509-3513.

, and C. M. Group, 2005: El Niño- or La Niña-like climate change? Climate Dyn., 24, 89-104.

Corrège, T., T. Delcroix, J. Récy, W. Beck, G. Cabioch, and F. L. Cornee, 2000: Evidence for stronger El Niño-Southern

Oscillation (ENSO) events in a mid-Holocene massive coral. Paleoceanography, 15, 465-470.

De Witt, D. G., and E. K. Schneider, 1998: The tropical ocean response to a change in orbital forcing. Center for Ocean-LandAtmosphere Studies Tech. Rep. 56, 55 pp.

, and _ 2000: The tropical ocean response to a change in solar forcing. J. Climate, 13, 1133-1149.

Felis, T., G. Lohmann, H. Kuhnert, S. Lorenz, D. Scholz, J. Pätzold, A. A. Rousan, and S. Al-Moghrabi, 2004: Increased seasonality in Middle East temperatures during the last interglacial period. Nature, 429, 164-168.

Gill, A., 1980: Some simple solutions for heat induced tropical circulation. Quart. J. Roy. Meteor. Soc, 106, 447-462.

Guilyardi, E., 2006: El Niño-mean state-seasonal cycle interactions in a multi-model ensemble. Climate Dyn., 26, 329-348.

Hughen, K. A., D. P. Schrag, and S. B. Jacobsen, 1999: El Niño during the last interglacial period recorded by a fossil coral from Indonesia. Geophys. Res. Lett., 26, 3129-3132.

Jackson, C, and A. Broccoli, 2003: Orbital forcing of arctic climate: Mechanisms of climate response and implications for continental glaciation. Climate Dyn., 21, 539-557.

Jin, F.-F., 1997: An equatorial ocean recharge paradigm for ENSO. Part I: Conceptual model. J. Atmos. Sci., 54, 811-829.

, J. Neelin, and M. Ghil, 1994: El Niño on the Devil's Staircase: Annual subhaimonic steps to chaos. Science, 264, 70-72.

Latif, M., and Coauthors, 2001: ENSIP: The EI Niño Simulation Intercomparison Project. Climate Dyn., 18, 255-276.

Lea, D., D. K. Pak, and H. J. Spero, 2000: Climate impact of late quaternary equatorial Pacific sea surface temperature variations. Science, 289, 1719-1724.

Legutke, S., and R. Voss, 1999: The Hamburg atmosphere-ocean coupled circulation model ECHO-G. German Climate Computer Center (DKRZ) Tech. Rep. 18, 62 pp.

Li, T., and S. G. H. Philander, 1996: On the annual cycle of the eastern equatorial Pacific. J. Climate, 9, 2986-2998.

Lindzen, R., and S. Nigam, 1987: On the role of sea surface temperature gradients in forcing low-level winds and convergence in the tropics. J. Atmos. Sci, 44, 2418-2436.

Liu, Z., 1998: On the role of ocean in the response of tropical climatology to global warming: The west-east SST contrast. J. Climate, 11, 864-875. 2002: A simple model study of ENSO suppression by external periodic forcing. J. Climate, 15, 1088-1098. 
, J. Kutzbach, and L. Wu, 2000: Modeling climate shift of El Niño variability in the holocene. Geophys. Res. Lett, 27, 2265-2268.

S.-I. Shin, B. Otto-Bliesner, J. E. Kutzbach, E. C. Brady, and D. Lee, 2002: Tropical cooling at the Last Glacial

Maximum and extratropical ocean ventilation. Geophys. Res. Lett., 29, 1409, doi:10.1029/2001GL013938.

, E. Brady, and J. Lynch-Steiglitz, 2003: Global ocean response to orbital forcing in the Holocene. Paleoceanography, 18, 1041, doi:10.1029/2002PA000819.

Lorenz, S., and G. Lohmann, 2004: Acceleration technique for Milankovitch type forcing in a coupled atmosphere-ocean circulation model: Method and application for the Holocene. Climate Dyn., 23, 727-743.

Mechoso, C., and Coauthors, 1995: The seasonal cycle over the tropical Pacific in coupled ocean-atmosphere general circulation models. Mon. Wea. Rev., 123, 2825-2838.

Min, S.-K., S. Legutke, A. Hense, and W.-T. Kwon, 2005: Internal variability in a 1000-yr control simulation with the coupled climate model ECHO-G-II. EI Niño Southern Oscillation and North Atlantic Oscillation. Tellus, 57 A, $622-640$.

Moy, C. M., G. O. Seltzer, D. T. Rodbell, and D. Anderson, 2002: Variability of EI Niño/Southern Oscillation activity at millennial timescales during the Holocene epoch. Nature, 420, 162-165.

Oberhuber, J., 1988: An atlas based on "COADS" data set. MaxPlanck-Institut für Meteorologie Tech. Rep. 15, 20 pp.

Otto-Bliesner, B. L., 1999: El Niño/La Niña and Sahel precipitation during the middle Holocene. Geophys. Res. Lett., 26, 8790.

E. C. Brady, S.-I. Shin, Z. Liu, and C. Shields, 2003: Modeling El Niño and its tropical teleconnections during the last glacial-interglacial cycle. Geophys. Res. Lett., 30, 2198, doi:10.1029/2003GL018553.

Pacanowski, R. C., and S. G. H. Philander, 1981: Parameterization of vertical mixing in numerical models of tropical oceans. J. Phys. Oceanogr., 11, 1443-1451.

Philander, S. G. H., D. Gu, G. Lambert, T. Li, D. Halpern, N.-C. Lau, and R. C. Pacanowski, 1996: Why the ITCZ is mostly north of the equator. J. Climate, 9, 2958-2972.

Philip, S., and G. van Oldenborgh, 2006: Shifts in ENSO coupling processes under global warming. Geophys. Res. Lett., 33, L11704, doi:10.1029/2006GL026196.

Rittenour, T. M., J. Brighan-Grette, and M. Mann, 2000: El Niño-like climate teleconnection in New England during the late Pleistocene. Science, 288, 1039-1042.

Rodbell, D., G. Seltzer, D. Anderson, M. Abbott, D. Enfield, and J. Newman, 1999: An 15,000-year record of El Niño-driven alluviation in southwestern Ecuador. Science, 283, 516-520.

Rodgers, K. B., P. Friedrichs, and M. Latif, 2004: Tropical Pacific decadal variability and its relation to decadal modulations of ENSO. J. Climate, 17, 3761-3774.

Roeckner, E., and Coauthors, 1996: The atmospheric general circulation model ECHAM-4: Model description and simulation of present-day climate. Max Planck Institute for Meteorology Tech. Rep. 218.

Sandweiss, D. H., J. B. Richardson, E. J. Reitz, H. B. Rollins, and K. A. Maasch, 1996: Geoarcheological evidence from Peru for a 5000 year BP onset of EI Niño. Science, 273, 1531-1533.

Sausen, R., K. Barthel, and K. Hasselmann, 1988: Coupled ocean-atmosphere models with flux correction. Climate Dyn., 2, 145-163.

Timm, O., and A. Timmermann, 2007: Simulation of the last 21000 years using accelerated transient boundary conditions. J. Climate, in press.

Timmermann, A., 2001: Changes of ENSO stability due to greenhouse warming. Geophys. Res. Lett., 28, $2064-2068$. , M. Latif, A. Bacher, J. Oberhuber, and E. Roeckner, 1999: Increased El Niño frequency in a climate model forced by

future greenhouse warming. Nature, 398, 694-696.

,F.F. Jin, and M. Collins, 2004a: Intensification of the annual cycle in the tropical Pacific due to greenhouse warming.

Geophys. Res. Lett., 31, L12208, doi:10.1029/2004GL019442.

, F. Justino, F.-F. Jin, and H. Goosse, 2004b: Surface temperature control in the North and tropical Pacific during the last

glacial maximum. Climate Dyn., 23, 353-370.

, S.-I. An, U. Krebs, and H. Goosse, 2005: ENSO suppression due to weakening of the North Atlantic thermohaline

circulation. J. Climate, 18, 3122-3139.

, and Coauthors, 2007: The influence of a weakening of the Atlantic meridional overturning circulation on ENSO. J.

Climate, in press.

Torrence, C., and G. P. Compo, 1998: A practical guide to wavelet analysis. Bull. Amer. Meteor. Soc, 79, 61-78.

Tudhope, A., and Coauthors, 2001: Variability in the EI Niño-Southern Oscillation through a glacial-interglacial cycle. Science, 291, 1511-1517.

Tziperman, E., L. Stone, M. Cane, and H. Jarosh, 1994: El Niño chaos: Overlapping of resonances between the seasonal cycle and the Pacific Ocean-atmosphere oscillator. Science, 264, 72-74.

Xie, S.-P., 1994: On the genesis of the equatorial annual cycle. J. Climate, 7, 2008-2013. 1996: Effects of seasonal solar forcing on latitudinal asymmetry of the ITCZ. J. Climate, 9, 2945-2950.

1997: Stability of equatorially symmetric and asymmetric climates under annual solar forcing. Quart. J. Roy. Meteor. Soc, $123,1359-1375$.

Zebiak, S. E., and M. A. Cane, 1987: A model El Niño-Southern Oscillation. Mon. Wea. Rev., 115, $2262-2278$.

\section{[Author Affiliation]}

A. TIMMERMANN

IPRC, SOEST, University of Hawaii at Manoa, Honolulu, Hawaii

S. J. LORENZ

Max Planck Institute for Meteorology, Hamburg, Germany

S.-I. AN

Department of Atmospheric Sciences, Yonsei University, Seoul, South Korea 


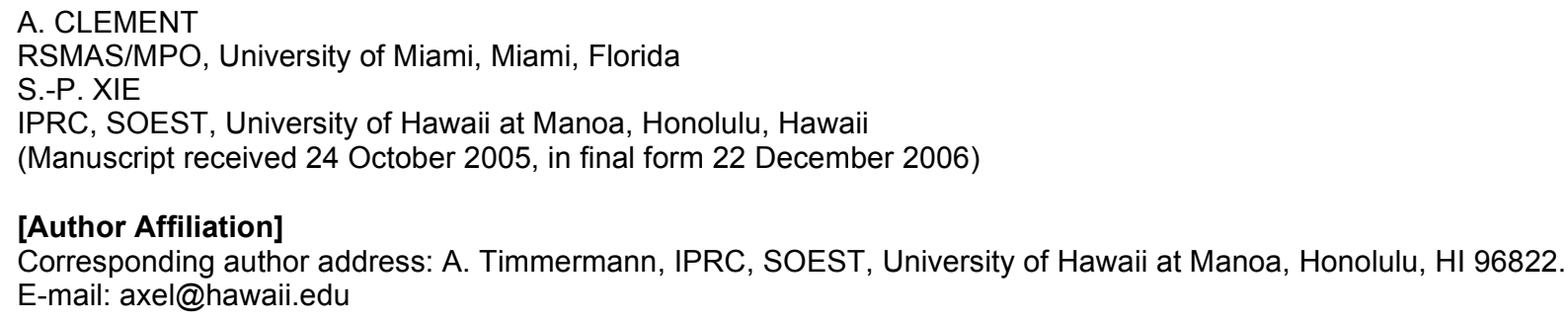

Subjects:

Author(s):

Author Affiliation:

Document types:

Document features:

Publication title:

Source type:

ISSN:

ProQuest document ID: 1325480531

Text Word Count

Document URL:

S.-I. AN

S.-P. XIE

\section{Feature}

Periodical

08948755

\section{6}

Temperature, Simulation, Climate change, General circulation models, Studies

A Timmermann, S J Lorenz, S-I An, A Clement, S-P Xie

A. TIMMERMANN

IPRC, SOEST, University of Hawaii at Manoa, Honolulu, Hawaii

S. J. LORENZ

Max Planck Institute for Meteorology, Hamburg, Germany

Department of Atmospheric Sciences, Yonsei University, Seoul, South Korea

A. CLEMENT

RSMAS/MPO, University of Miami, Miami, Florida

IPRC, SOEST, University of Hawaii at Manoa, Honolulu, Hawaii

(Manuscript received 24 October 2005, in final form 22 December 2006)

Corresponding author address: A. Timmermann, IPRC, SOEST, University of Hawaii at Manoa, Honolulu, HI 96822.

E-mail: axel@hawaii.edu

Graphs, Photographs, Diagrams, References

Journal of Climate. Boston: Aug 15, 2007. Vol. 20, Iss. 16; pg. 4147, 13 pgs

http://proquest.umi.com/pqdweb?did=1325480531\&sid=31\&Fmt=3\&c lientld=8631\&RQT=309\&VName=PQD

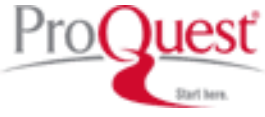

